\title{
Recovery of Peniophora cinerea laccase using aqueous two-phase systems composed by ethylene oxide/propylene oxide copolymer and potassium phosphate salts
}

\author{
Sérgio Moreira ${ }^{a}$, Sara C. Silvério ${ }^{\mathrm{b}, \mathrm{c}}$, Eugénia A. Macedo ${ }^{\mathrm{c}}$, Adriane M.F. Milagres $^{\mathrm{a}}$, \\ José A. Teixeirab ${ }^{\mathrm{b}}$, Solange I. Mussatto ${ }^{\mathrm{b}, *}$ \\ a Department of Biotechnology, Engineering College of Lorena, University of São Paulo, Estrada Municipal do Campinho s/n, CEP, 12602-810 Lorena/SP, \\ Brazil \\ ${ }^{\mathrm{b}}$ Institute for Biotechnology and Bioengineering (IBB), Centre of Biological Engineering, University of Minho, Campus de Gualtar, $4710-057$ Braga, Portugal \\ ${ }^{\mathrm{c}}$ Laboratory of Separation E Reaction Engineering, Associate Laboratory LSRE/LCM, Faculty of Engineering, University of Porto, Rua Dr. Roberto Frias, s/n, \\ 4200-465 Porto, Portugal
}

\section{A R T I C L E I N F O}

\section{Article history:}

Received 16 June 2013

Received in revised form

25 September 2013

Accepted 15 October 2013

Available online 25 October 2013

\section{Keywords:}

Aqueous two-phase systems

Purification

Laccase

Phosphate salts

UCON

\begin{abstract}
A B S T R A C T
Aqueous two-phase systems (ATPSs) composed by UCON (ethylene oxide/propylene oxide copolymer) and potassium phosphate salts were for the first time evaluated in the recovery of Peniophora cinerea laccase from complex fermented medium. The ATPSs were obtained by combining the random copolymer UCON with $\mathrm{KH}_{2} \mathrm{PO}_{4}$, potassium phosphate buffer $\mathrm{pH} 7$ or $\mathrm{K}_{2} \mathrm{HPO}_{4}$. According to the results, protein partition occurred predominantly toward the saline phase (bottom phase) of the ATPSs, while some contaminants such as pigments partitioned mainly to the top phase. In preliminary tests, it was found that the salt with the lowest $\mathrm{pH}$ value $\left(\mathrm{KH}_{2} \mathrm{PO}_{4}, \mathrm{pH} 4.6\right)$ stimulated the enzyme activity, while the other salts (pH between 7.0 and 9.5) caused a strong inhibition. However, the salt inhibition was not observed in the equilibrium phases of the UCON-Potassium phosphate ATPSs. The laccase recovery was high for all the biphasic systems, but the highest value (134\%) was obtained when using UCON combined with $\mathrm{KH}_{2} \mathrm{PO}_{4}$. When compared to conventional concentration and purification methods (lyophilization, ammonium sulfate precipitation, ultrafiltration, and ion exchange chromatography), ATPS was demonstrated to be an efficient alternative for $P$. cinerea laccase recovery from fermented medium.
\end{abstract}

(C) 2013 Elsevier B.V. All rights reserved.

\section{Introduction}

Laccases are oxidoreductases commonly produced by white-rot fungi. These enzymes present several biotechnological applications including delignification of lignocellulosic materials, effluents decolorization, bioremediation, and organic synthesis. Laccases normally occur as extracellular glycoproteins, being produced in the cells and then secreted and accumulated outside the hyphal filaments [1]. The purification of laccases from cultures of basidiomycetes has been performed by different methods, generally involving multiple high cost and time spent chromatographic procedures [2,3]. Frequently a four or five steps methodology is used for laccase purification, based on an initial concentration of the cultivation extract by precipitation with ammonium sulfate or ultrafiltration, followed by ion exchange, gel permeation and/or

\footnotetext{
* Corresponding author. Tel.: +351 253604424; fax: +351 253604429.

E-mail addresses: solange@deb.uminho.pt, solangemussatto@hotmail.com (S.I. Mussatto).
}

affinity chromatography [4]. The combination of several chromatographic methods provides a considerable increase in the laccase purification factor. However, the purification yields of the enzyme from ligninolytic fungi cultivation (both under submerged or solidstate fermentation conditions) are usually low [5]. This aspect limits the biotechnological application of laccase, since significant amounts of enzyme are needed to efficiently compete with the traditional oxygen- and chlorine-based oxidizing agents $\left(\mathrm{Cl}_{2}, \mathrm{ClO}_{2}, \mathrm{O}_{2}\right.$, $\mathrm{O}_{3}$ or $\mathrm{H}_{2} \mathrm{O}_{2}$ ) [6]. In addition, Peniophora cinerea, as well as several other laccase-producing fungi, produces also pigments during the fermentation $[7,8]$, and such compounds may affect the enzyme purification process [9].

The use of complex fermentation media containing agroindustrial waste residues, such as the corn steep liquors (a residue from wet processing of corn), is an interesting alternative for laccase production from ligninolytic fungi [7]. This approach reduces both the pollution problems caused by residue accumulation and the costs associated to the bioprocess. Furthermore, complex media can significantly promote the laccase production [10]. Nevertheless, the use of these kinds of media may bring additional 
Table 1

Feed and phase composition of the UCON-potassium phosphate ATPSs ${ }^{\mathrm{a}}$.

\begin{tabular}{|c|c|c|c|c|c|c|}
\hline \multirow[t]{2}{*}{ ATPS } & \multicolumn{2}{|l|}{ Feed } & \multicolumn{2}{|l|}{ Top phase } & \multicolumn{2}{|l|}{ Bottom phase } \\
\hline & UCON (\%) (w/w) & Salt (\%) (w/w) & $\operatorname{UCON}(\%)(w / w)$ & Salt (\%) (w/w) & UCON (\%) (w/w) & Salt (\%) (w/w) \\
\hline $\mathrm{UCON}-\mathrm{KH}_{2} \mathrm{PO}_{4}$ & 17.2 & 7.6 & 31.7 & 3.3 & 0.3 & 12.6 \\
\hline $\mathrm{UCON}-\mathrm{KPB}^{\mathrm{b}}$ & 14.0 & 5.7 & 26.7 & 2.4 & 0.6 & 9.1 \\
\hline $\mathrm{UCON}-\mathrm{K}_{2} \mathrm{HPO}_{4}$ & 20.0 & 4.0 & 28.6 & 2.0 & 0.3 & 8.3 \\
\hline
\end{tabular}

a Data from [22].

b KPB-Potassium phosphate buffer $1 \mathrm{M}, \mathrm{pH} 7.0$.

contaminants (like phenolic compounds or metals) that can compromise the enzymatic activity.

Liquid-liquid extraction using aqueous two-phase systems (ATPSs) could be an alternative to the conventional methods of purification. Traditional ATPSs are prepared by mixing aqueous solutions of two polymers, or a polymer and a salt [11]. The solutions become immiscible above critical conditions like temperature or concentration, and a biphasic system is formed, as a consequence. Both phases are mainly composed by water (70-90\%), but each one of them is enriched in a different component. The high percentage of water in ATPS provides a mild environment for the recovery and purification of sensitive biological materials, such as proteins [12], cells [13], cell fragments and nucleic acids [14]. Purification is achieved when the target molecule is predominantly partitioned to one of the phases, while the interfering substances (contaminants) are partitioned to the opposite phase of the system. The most interesting features of ATPSs include their scaling up feasibility, process integration capability and biocompatibility. Compared to other techniques, such as chromatography, ATPSs present economic and technical advantages by reducing both the number of steps and the associated costs [15].

The use of ATPSs for laccase recovery from diverse fungi sources has been reported in the literature [16-18]. However, in all these works the ATPSs were formed by polyethylene glycol (PEG) with different molecular weight and phosphate salts. As far as we know, no references are found on the use of UCON-salt ATPSs for laccase recovery from fermentation media.

In the last decades, the use of thermo-sensitive polymers has been introduced in ATPSs to facilitate polymer recovery [19]. Random copolymers constituted by ethylene oxide (EO) and propylene oxide (PO) units, like UCON, are examples of interesting thermoresponsive (or thermo separating) polymers. The main advantage of EOPO copolymers is that they can suffer significant changes in their solubility due to small variations occurred in temperature. When heated above the lower critical solution temperature (LCST) these polymers separate from the aqueous solution. As a consequence, a new biphasic system composed by a water-rich phase and a polymer-rich phase is formed. This important feature facilitates polymer recovery and makes its reutilization possible. The LCST for the thermo-responsive UCON used in the present study, is about $50^{\circ} \mathrm{C}$ [20]. PEG is also a thermo-separating polymer, but its LCST is above $100^{\circ} \mathrm{C}$ [21], which is too high for applications involving labile molecules. The relatively low LCST of UCON, and the advantages associated with the polymer recovery process were the main reasons for choosing this polymer for UCON-salt ATPSs formation.

The present study evaluated for the first time the use of UCONpotassium phosphate salts ATPSs for the recovery of $P$. cinerea laccase from complex fermented medium. The previously characterized ATPSs [22] were obtained by combining UCON with $\mathrm{KH}_{2} \mathrm{PO}_{4}$, potassium phosphate buffer $\mathrm{pH} 7$ or $\mathrm{K}_{2} \mathrm{HPO}_{4}$. These ATPSs were selected after a screening study where both the partition and stability of a pure commercial laccase from Trametes versicolor was evaluated [23]. In the present work a different fungal source $(P$. cinerea) was used to produce laccase. Furthermore, the enzyme was recovered from a complex medium where several other compounds are also present. The results obtained using ATPSs were compared with those achieved by using conventional methods of concentration and purification (lyophilization, ammonium sulfate precipitation, ultrafiltration or ion exchange chromatography) and also with those reported in the literature using PEG-phosphate ATPSs.

\section{Material and methods}

\subsection{Chemicals and stock solutions}

UCON 50-HB-5100, a random copolymer (average molecular weight $M_{r}=3900$ ) with $50 \%$ ethylene oxide and $50 \%$ propylene oxide, was obtained from Union Carbide (NY, USA). Potassium dihydrogen phosphate $\left(\mathrm{KH}_{2} \mathrm{PO}_{4}\right)$ (anhydrous, 99.9\%) was provided by USB Corporation. Dipotassium hydrogen phosphate $\left(\mathrm{K}_{2} \mathrm{HPO}_{4}\right)$ (anhydrous, 99.99\% Suprapur) was supplied by Merck (Germany). 2,2'-azino-bis-3-ethylbenzothiazoline-6sulfonate (ABTS) was obtained from Sigma-Aldrich (Germany). Coomassie ${ }^{\circledR}$ Protein Assay Reagent and BSA Standard Ampules were purchased from Pierce Biotechnology. All chemicals were used as obtained, i.e., without further purification.

Milli Q water was used to prepare stock solutions of UCON and potassium phosphate salts (ca. $50 \mathrm{wt} \%$ for UCON, $15.5 \mathrm{wt} \%$ for $\mathrm{KH}_{2} \mathrm{PO}_{4}$, and $20 \mathrm{wt} \%$ for $\left.\mathrm{K}_{2} \mathrm{HPO}_{4}\right)$. The concentrations were obtained gravimetrically after evaporation on a heating plate (Stuart hot plate SB300) for salts, or after lyophilization (Scan Vac, model CoolSafe 55-4) for UCON. Potassium phosphate buffer (1 M, $\mathrm{pH}$ 7.0) was prepared by combining $\mathrm{KH}_{2} \mathrm{PO}_{4}$ and $\mathrm{K}_{2} \mathrm{HPO}_{4}$ salts; and its concentration (ca. $14 \mathrm{wt} \%$ ) was adjusted gravimetrically after evaporation on a heating plate. All the weightings were carried out on an Adam Equipment balance model AAA250L, with precision of $0.2 \mathrm{mg}$.

\subsection{Fungal strain and laccase production}

P. cinerea CCIBT2541 from the Culture Collection of the Institute of Botany (São Paulo, Brazil), was the fungal strain utilized in the experiments. Cultures of this fungus were maintained in potato dextrose agar (PDA) at $4{ }^{\circ} \mathrm{C}$. To be used in the experiments, three disks $(\varnothing 7 \mathrm{~mm}$ ) of fungal colonies grown in PDA medium during 7 days at $28^{\circ} \mathrm{C}$ were inoculated in 250 -mL Erlenmeyer flasks containing $50 \mathrm{~mL}$ of liquid culture medium composed of sucrose $(5 \mathrm{~g} / \mathrm{L})$, $\mathrm{KH}_{2} \mathrm{PO}_{4}(0.2 \mathrm{~g} / \mathrm{L}), \mathrm{MgSO}_{4} \cdot 7 \mathrm{H}_{2} \mathrm{O}(0.05 \mathrm{~g} / \mathrm{L}), \mathrm{MnSO}_{4} \cdot \mathrm{H}_{2} \mathrm{O}(0.016 \mathrm{~g} / \mathrm{L})$, $\mathrm{CaCl}_{2} \cdot 2 \mathrm{H}_{2} \mathrm{O}(0.013 \mathrm{~g} / \mathrm{L}), \mathrm{CuSO}_{4} \cdot 5 \mathrm{H}_{2} \mathrm{O}(1 \mathrm{mM})$ and corn steep liquor $0.5 \%(\mathrm{v} / \mathrm{v})$. Cultivation was maintained at $25^{\circ} \mathrm{C}$ under static conditions, during 20 days. After this period, liquid cultures were harvested, filtered through $0.45 \mu \mathrm{m}$ membrane, and concentrated by using ammonium sulfate (80\% saturation). The extract of $P$. cinerea laccase then obtained was used in all the subsequent purification assays. 

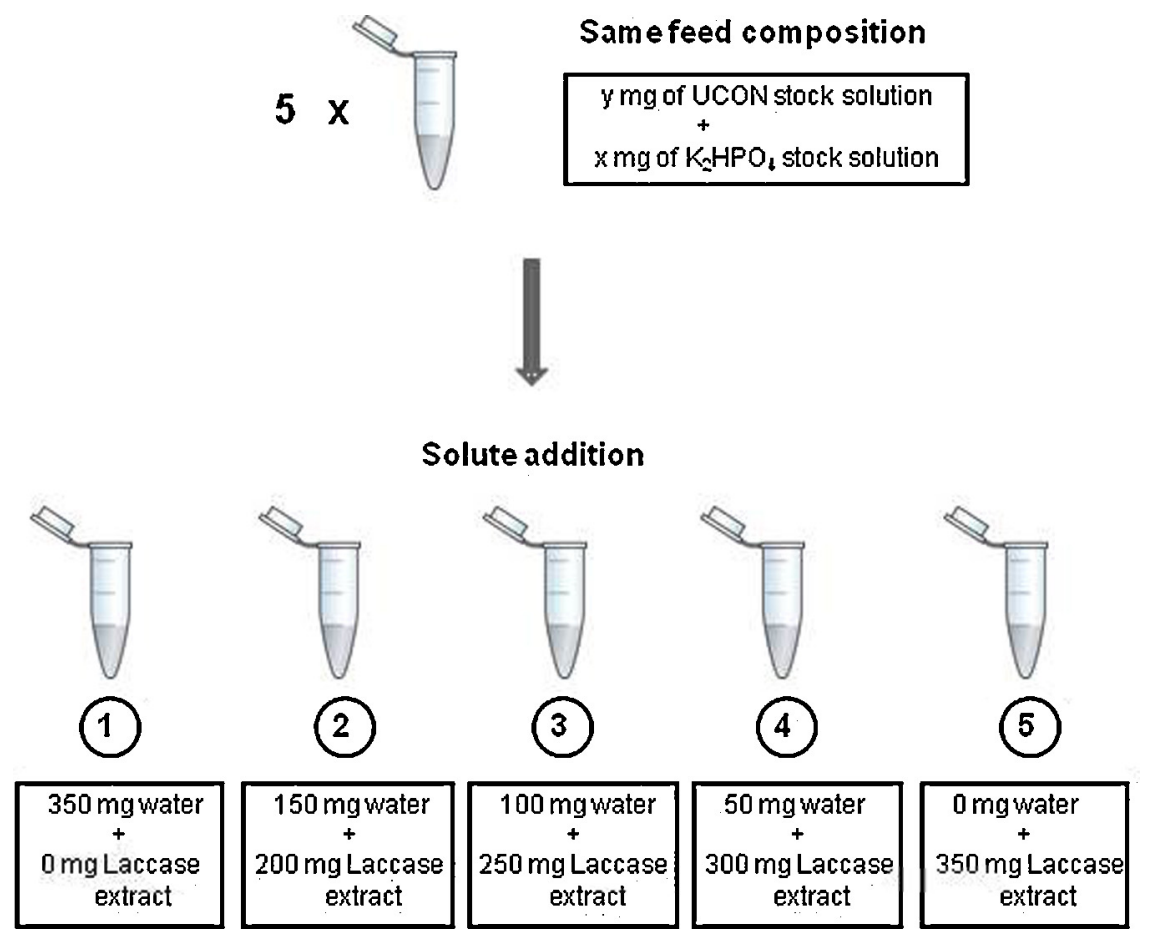

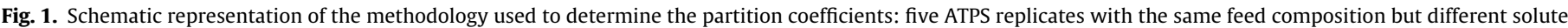
concentration.

\subsection{Laccase recovery by ATPS}

Initially, assays were carried out in order to evaluate the interference of potassium phosphate salts and UCON in the laccase activity. $P$. cinerea laccase extract was previously incubated (static conditions, room temperature) with different concentrations of salts $\left(\mathrm{KH}_{2} \mathrm{PO}_{4}, \mathrm{~K}_{2} \mathrm{HPO}_{4}\right.$ or potassium phosphate buffer $\left.\mathrm{pH} 7.0\right)$ and UCON, during $30 \mathrm{~min}$. The laccase activity was then determined and the values of relative activity (\%) were calculated taking into account a control assay obtained by incubating only the $P$. cinerea laccase extract at room temperature for $30 \mathrm{~min}$.

To obtain each biphasic system, appropriated amounts of polymer and salt stock solutions were mixed in 1.5 -mL eppendorf tubes. Final composition of the prepared systems is indicated in Table 1. For each ATPS, five replicates with the same feed composition but containing from 0 up to $350 \mathrm{mg}$ of $P$. cinerea laccase extract were prepared. The corresponding amount of water (from 350 to $0 \mathrm{mg}$ ) was added to keep all compositions constant, except for $P$. cinerea laccase extract (to obtain partition coefficients independent from solute concentration). A schematic representation of this procedure is illustrated in Fig. 1 for UCON-K $\mathrm{HPO}_{4}$ ATPS. The tubes were then thoroughly mixed on a vortex mixer for $2 \mathrm{~min}$, and phase separation was achieved by centrifugation (10,000 rpm, $10 \mathrm{~min}$ ) with temperature controlled to $23^{\circ} \mathrm{C}$. Samples of each phase were withdrawn and conveniently diluted with water, and analyzed for total protein and laccase activity determinations. All experiments were carried out at room temperature controlled to $23^{\circ} \mathrm{C}$.

Partition coefficients $\left(K_{p}\right)$ were determined as the slope of the straight line obtained when comparing the protein concentration in the top phase $\left(C_{T}\right)$ against that in the bottom phase $\left(C_{B}\right)$, for the five replicates prepared:

$K_{p}=\frac{C_{T}}{C_{B}}$

The specific activity in a given equilibrium phase ( $S A$, in $\mathrm{U} / \mathrm{mg}$ ), was calculated as the ratio between enzyme activity in the equilibrium phase $\left(A_{\text {phase}}\right.$, in $\left.\mathrm{U} / \mathrm{L}\right)$ and the total protein concentration in the same equilibrium phase $\left(C_{\text {phase }}\right.$, in $\left.\mathrm{mg} / \mathrm{L}\right)$ :

$S A=\frac{A_{\text {phase }}}{C_{\text {phase }}}$

The purification factor $(P F)$, was determined as the ratio between specific activity in the enzyme-rich phase $\left(S A_{\text {phase }}\right)$ and the initial specific activity in the extract $\left(S A_{\text {ext }}\right)$ :

$P F=\frac{S A_{\text {phase }}}{S A_{\text {ext }}}$

The activity recovery yield was obtained from the ratio between enzyme activity in the enzyme-rich phase $\left(A_{\text {phase }}\right)$ and the initial enzyme activity in the extract $\left(A_{\text {ext }}\right)$ :

$\%$ Activity yield $=\left[\frac{\left(A_{\text {phase }} \times V_{\text {phase }}\right)}{\left(A_{\text {ext }} \times V_{\text {ext }}\right)}\right] \times 100$

The protein recovery yield was calculated using the value of $K_{p}$ and the volume ratio ( $V R$, defined as the ratio between top and bottom phase volumes):

$\%$ Protein yield $=\frac{100}{1}+\left[\frac{1}{\left(V R \times K_{p}\right)}\right]$

\subsection{Laccase recovery by concentration and purification methods}

Four conventional purification/concentration methods, namely lyophilization, ammonium sulfate precipitation, ultrafiltration, and ion exchange chromatography were also tested for laccase recovery from crude extract of $P$. cinerea. The freeze drying method was initially used for the laccase concentration, and consisted in subjecting the previously frozen $\left(-20^{\circ} \mathrm{C}\right)$ enzyme extract in a vacuum lyophilization equipment. For the ammonium sulfate precipitation, the laccase extract was precipitated with ammonium sulfate (at $90 \%$ saturation) at $4{ }^{\circ} \mathrm{C}$ for $12 \mathrm{~h}$. After this time, the formed precipitate was resuspended in sodium acetate buffer $10 \mathrm{mM}, \mathrm{pH} 5.2$, 
Table 2

Influence of the ATPS (aqueous two-phase systems) constituents in the Peniophora cinerea laccase activity.

\begin{tabular}{|c|c|c|c|}
\hline \multicolumn{3}{|c|}{ ATPS constituent } & \multirow[t]{2}{*}{ Relative laccase activity ${ }^{\mathrm{a}}$} \\
\hline Salts & $\begin{array}{l}\text { Concentration } \\
\text { (wt\%) }\end{array}$ & $\begin{array}{l}\mathrm{pH} \text { of the } \\
\text { solution }\end{array}$ & \\
\hline $\mathrm{KH}_{2} \mathrm{PO}_{4}$ & $\begin{array}{l}7.5 \\
15\end{array}$ & 4.60 & $\begin{array}{l}153 \\
161\end{array}$ \\
\hline $\mathrm{K}_{2} \mathrm{HPO}_{4}$ & $\begin{array}{l}5 \\
10\end{array}$ & 9.46 & $\begin{array}{l}0 \\
0\end{array}$ \\
\hline $\mathrm{KPB}^{\mathrm{b}}$ & $\begin{array}{l}7 \\
14\end{array}$ & 7.09 & $\begin{array}{l}1 \\
2\end{array}$ \\
\hline UCON & $\begin{array}{l}25 \\
50\end{array}$ & - & $\begin{array}{l}89 \\
24\end{array}$ \\
\hline
\end{tabular}

a Relative activity (\%) was calculated taking into account a control assay using only the $P$. cinerea laccase extract, i.e., in absence of UCON and phosphate salts or buffer. ${ }^{\mathrm{b}} \mathrm{KPB}-$ Potassium phosphate buffer, $1 \mathrm{M}$, pH 7.0.

and dialyzed for the salt removal. Ultrafiltration was carried out in Falcon tubes with $3 \mathrm{kDa}$ membranes (Millipore) at $8000 \mathrm{rpm}$ for $15 \mathrm{~min}$. Finally, ion exchange chromatography was performed on a DEAE-Sepharose CL-6B anion exchange column $(1.5 \times 12 \mathrm{~cm})$. The laccase extract was loaded onto the column previously equili-

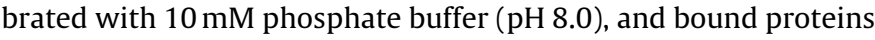
were eluted with $25 \mathrm{~mL}$ of $0.2 \mathrm{M} \mathrm{NaCl}$. The collected fractions were dialyzed and analyzed for laccase activity and total protein.

\subsection{Analytical procedures}

Laccase activity was determined spectrophotometrically using $1 \mathrm{mM}$ 2,2'-azino-bis-3-ethylbenzothiazoline-6-sulfonate (ABTS) as substrate in $50 \mathrm{mM}$ phosphate-citrate $\mathrm{pH} 4.0$, at $25^{\circ} \mathrm{C}$. The absorbance was measured at $420 \mathrm{~nm}\left(\varepsilon=36.000 \mathrm{M}^{-1} \mathrm{~cm}^{-1}\right)$ [24]. One unit of laccase activity (U) was defined as the amount of enzyme required to oxidize $1 \mu \mathrm{mol}$ of ABTS radicals per min.

Protein concentration was determined by the Bradford assay [25] using the Coomassie reagent. Appropriate dilutions were made to minimize the interference of salts and UCON in the Bradford assay [26].

In all ATPS, laccase activity and total protein concentration were obtained as the average of three independent experiments.

\section{Results and discussion}

\subsection{Interference of potassium phosphate salts and UCON in the laccase activity}

In order to evaluate the interference of each ATPS constituent in the $P$. cinerea laccase activity, assays were carried out using salts and UCON concentrations close to those present in the equilibrium phases (Table 1 ). The results obtained for the relative laccase activity (\%) are given in Table 2 . As can be seen, phosphate salts showed different interferences in $P$. cinerea laccase activity. The enzymatic activity was increased when in presence of $\mathrm{KH}_{2} \mathrm{PO}_{4}$, but it was strongly inhibited in the presence of $\mathrm{K}_{2} \mathrm{HPO}_{4}$ or potassium phosphate buffer. A possible explanation for these results could be the $\mathrm{pH}$ of the salt solutions. Since fungal laccases usually exhibit $\mathrm{pH}$ optima in the acidic $\mathrm{pH}$ range [27], no enzymatic activity was observed in the presence of the phosphate salts with the highest $\mathrm{pH}$ values. On the contrary, the laccase activity was stimulated in the presence of $\mathrm{KH}_{2} \mathrm{PO}_{4}$ salt, whose solution had a low $\mathrm{pH}$ value.

Regarding the UCON interference tests, two different concentrations of polymer were chosen: one close (25\%) and other higher (50\%) than those found in the ATPSs. It was found a strong interference of UCON in the enzymatic activity (24\% relative laccase activity) when present in higher concentrations. However, when
Table 3

Partition coefficient obtained for total proteins in the different aqueous two-phase systems (ATPS).

\begin{tabular}{ll}
\hline ATPS & $K_{p}{ }^{\mathrm{a}}$ \\
\hline $\mathrm{UCON} / \mathrm{K}_{2} \mathrm{HPO}_{4}$ & $0.238 \pm 0.008$ \\
$\mathrm{UCON} / \mathrm{KPB}^{\mathrm{b}}$ & $0.309 \pm 0.013$ \\
$\mathrm{UCON} / \mathrm{KH}_{2} \mathrm{PO}_{4}$ & $0.504 \pm 0.018$ \\
\hline
\end{tabular}

a Partition coefficient $\left(K_{p}\right)$, calculated from the slope of the straight line obtained when plotting the protein concentration in the top phase against the protein concentration in the bottom phase.

b KPB-Potassium phosphate buffer 1 M, pH 7.0.

present in a concentration close to those founded in the top phase of UCON-phosphate salt ATPSs, an activity variation of only $11 \%$ was found. Some synthetic polymers have been described as stabilizing agents of enzymes due to their ability to exclude the enzyme from part of the solvent, thus minimizing the detrimental effect of the environment [28]. Polyethylene glycol (PEG) is one of these polymers, and its effect at suppressing the inactivation of enzymes [29], including laccase [30], is reported in the literature. UCON, such as PEG, is composed by ethylene oxide, but it also contains propylene oxide units and for that reason it is more hydrophobic than PEG. This characteristic may explain the decrease in the enzymatic activity observed in the presence of UCON, because being more hydrophobic, its interaction with the solvent is lower. Therefore the protective effect of UCON, minimizing the prejudicial interferences of the environment and contributing to the enzyme stabilization, seems to be lower. UCON interference in laccase activity was previously reported by our group [23], where it was showed that bottom phases (salt-rich phase) of UCON-phosphate salt ATPSs provided better stability results than top phases (UCON-rich phase). However, the specific mechanism involved in the UCON interaction with both the solvent and the enzyme is beyond the scope of this work. Furthermore, protein partitioned mainly to the bottom phase, where UCON concentration is much lower $(0.3-0.6 \% \mathrm{w} / \mathrm{w})$, thus its interference in laccase activity will be reduced. As a consequence, it can be concluded that UCON caused a small interference in the laccase activity when present in concentration close to those founded in the equilibrium phases.

\subsection{Laccase recovery by ATPS}

Table 3 summarizes the results obtained for protein partition coefficient $(K)$ in the different ATPSs studied. For each biphasic system, five replicates with different laccase concentrations were prepared. A straight line was obtained when protein concentration in the top phase was plotted against laccase concentration in the bottom phase, for the five replicates, as illustrated in Fig. 2 for UCON-K $\mathrm{HPO}_{4}$ ATPS. Protein partition coefficient was obtained as the slope of this straight line, as previously described $[23,31]$. The only exception was UCON-KPB ATPS, where only four replicates were used to obtain the partition coefficient. This fact was due to the detection of some precipitation at the interface of the ATPS when the maximum volume of extract was added. Therefore, this point was rejected. Linearity was observed in all cases, which indicates that all partition coefficients calculated using this procedure have thermodynamic meaning (since they are independent of the solute concentration). This linearity also confirms that there are no inconvenient phenomena, like aggregation, affecting the partition coefficient.

The partition coefficients revealed that protein partition occurred preferably toward the bottom phase of the ATPSs. As shown in Table 4 , \% activity yield $>100$ were obtained in some cases, even for the ATPSs composed by salts that caused strong inhibition in laccase activity (Table 2). Contrary to the classical concept of recovery, yields over $100 \%$ can be found when evaluating the 


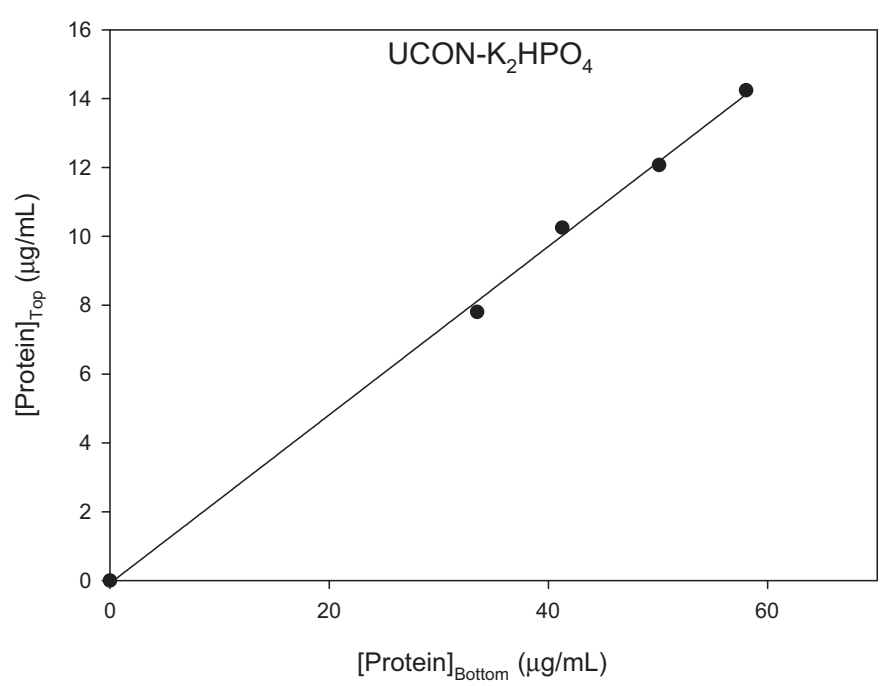

Fig. 2. Linear representation of the total protein concentration in top phase versus total protein concentration in the bottom phase for the five replicates of UCON$\mathrm{K}_{2} \mathrm{HPO}_{4}$ ATPS.

\section{Table 4}

Recovery of Peniophora cinerea laccase using UCON-Potassium phosphate ATPSs.

\begin{tabular}{llrrl}
\hline Extract added $(\mu \mathrm{L})$ & SA $(\mathrm{U} / \mathrm{mg})$ & PF & Activity Yield $(\%)$ & $\begin{array}{l}\text { Protein } \\
\text { Yield }(\%)\end{array}$ \\
\hline UCON-K $\mathrm{HPO}_{4}$ & & & & \\
200 & 70.9 & 1.61 & $107 \pm 4$ & $66 \pm 4$ \\
250 & 72.6 & 1.65 & $101 \pm 3$ & $61 \pm 5$ \\
300 & 57.9 & 1.32 & $81 \pm 4$ & $62 \pm 4$ \\
350 & 49.0 & 1.11 & $68 \pm 2$ & $61 \pm 3$ \\
$\mathrm{UCON}-\mathrm{KPB}^{\mathrm{a}}$ & & & & \\
150 & 48.6 & 1.11 & $88 \pm 3$ & $77 \pm 4$ \\
200 & 35.5 & 0.84 & $70 \pm 2$ & $78 \pm 4$ \\
250 & 32.9 & 0.75 & $67 \pm 3$ & $81 \pm 5$ \\
$\mathrm{UCON}-\mathrm{KH}_{2} \mathrm{PO}_{4}$ & & & & $72 \pm 4$ \\
200 & 67.8 & 1.31 & $134 \pm 4$ & $72 \pm 5$ \\
250 & 75.3 & 1.45 & $104 \pm 3$ & $68 \pm 4$ \\
300 & 75.7 & 1.46 & $99 \pm 3$ & $70 \pm 4$ \\
350 & 65.7 & 1.27 & $89 \pm 2$ & \\
\hline
\end{tabular}

a KPB-Potassium phosphate buffer $1 \mathrm{M}, \mathrm{pH} 7.0$ enzymatic activity [32,33]. The enzymatic activity depends on several factors such as the $\mathrm{pH}$, temperature or concentration of some components (salts, polymers, contaminants, etc.), and therefore it can be positively (or negatively) affected by variations occurred in the media. In this particular case, the increase over $100 \%$ can be a consequence of the removal to the top phase of some contaminants [34], such as the pigments present in the laccase extract which might inhibit the enzymatic activity. Visually, it was possible to confirm that pigments partitioned essentially to the top phase of the UCON-salt ATPSs, becoming this phase rather brown in all biphasic systems (Fig. 3). Besides the pigments, other compounds from the fermentation medium could be affecting laccase activity. Corn steep liquor was used to prepare the complex medium because it proved to enhance laccase production [7]; it is relatively inexpensive and commercially available. This liquor is mainly composed by peptides, lactic acid, reducing sugars, metal ions, amino acids and vitamins [35]. Some of these compounds might be affecting the laccase activity in the $P$. cinerea extract. Nevertheless, when the extract was added to the biphasic systems, some of these interfering compounds might be partitioned to the top phase and therefore laccase activity increase in the bottom phase leading to $\%$ activity yield $>100$.

Additionally, the volume of laccase extract added to the system influenced also the \% activity yield of the $P$. cinerea laccase in the bottom phase. In all cases, increasing the volume of enzyme extract added to the system caused a decrease in the \% activity yield in the bottom phase (Table 4). An analogous effect was reported for laccase extract from Agaricus bisporus, which was attributed to the saturation of the recovery phase due to the complex composition of the extract [36]. In this work, probably did not occur the saturation of the recovery phase (bottom phase), but the saturation of the top phase with the contaminants that negatively affect laccase activity. As a consequence, for higher volumes of added extract, the amount of contaminants partitioned to the bottom phase will increase, contributing for the decrease observed in the \% activity yield (Table 4). The purification factor also decreased for the higher volumes of laccase extract added to the ATPSs (Table 4). On the other hand, the $\%$ protein yield did not varied significantly when increasing the volume of laccase extract added (Table 4). Considering all the parameters presented in Table 4 , it was found that the best

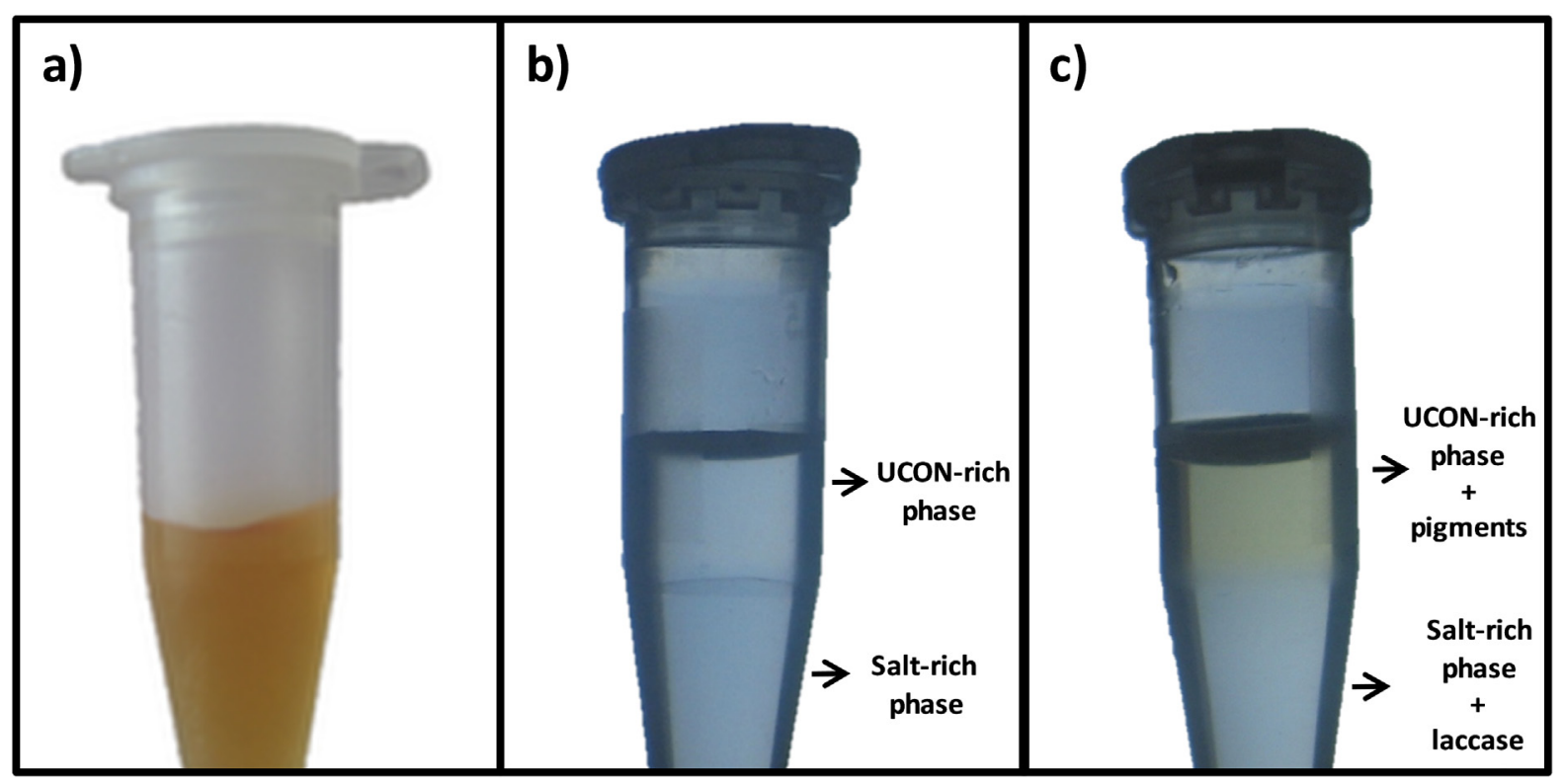

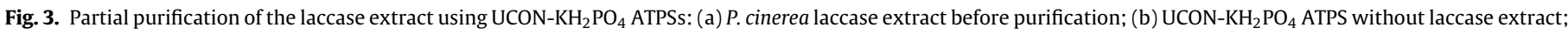
(c) UCON- $\mathrm{KH}_{2} \mathrm{PO}_{4}$ ATPS with laccase extract. 
Table 5

ATPSs used for fungal laccase recovery, together with the corresponding \% activity yields and purification factors.

\begin{tabular}{|c|c|c|c|c|}
\hline Microorganism & ATPS & Activity yield (\%) & $\mathrm{PF}$ & Ref. \\
\hline Peniophora cinerea & $\mathrm{UCON}-\mathrm{K}_{2} \mathrm{HPO}_{4}$ & $107-101$ & $1.61-1.65$ & This work \\
\hline Peniophora cinerea & $\mathrm{UCON}-\mathrm{KH}_{2} \mathrm{PO}_{4}$ & $134-104$ & $1.31-1.45$ & This work \\
\hline Agaricus bisporus & PEG1000-Phosphate pH 7 & 95 & 2.48 & {$[16]$} \\
\hline Lentinus polychrous & PEG4000-Phosphate pH 7 & 99 & 3.01 & [17] \\
\hline Pleurotus sapidus & PEG3000-Phosphate $\mathrm{pH} 7$ (addition of $\mathrm{NaCl}$ ) & 130 & $\mathrm{nr}$ & [18] \\
\hline
\end{tabular}

nr: not reported.

results for laccase recovery were obtained using $\mathrm{UCON}-\mathrm{K}_{2} \mathrm{HPO}_{4}$ and UCON- $\mathrm{KH}_{2} \mathrm{PO}_{4}$ ATPSs when lower volumes of extract were added to the system. These ATPSs provided the highest \% activity yields and purification factors, important issues when considering the practical application of laccase in oxidation process.

A comparison between the results obtained using UCONphosphate ATPSs and those reported in the literature for PEG-phosphate ATPSs is presented in Table 5 . The \% activity yields here achieved are higher or similar to those reported for PEGphosphate ATPSs. However, the purification factor is lower. It is important to highlight that we are comparing laccase extracts obtained from different fungal sources and through different fermentation conditions. Thus, the extracts certainly have a different composition regarding the amount of proteins and other contaminants present.

\subsection{Laccase recovery by concentration and purification methods}

Conventional methods of concentration and purification were also carried out and compared whit the laccase recovery results obtained using ATPSs (Table 6). Among the evaluated methods, lyophilization and ultrafiltration gave the lowest activity yields ( $48 \%$ and $41 \%$, respectively), and were considered unsuitable to recover laccase from $P$. cinerea extract. Lyophilization allows the simultaneous concentration of laccase and all the contaminants, which may explain the reduced activity yields obtained. In addition, lyophilization process can also induce denaturation by both freezing and drying stresses [37]. On the other hand, ultrafiltration eliminated all the extract components with lower molecular weight, which include some ions (such as $\mathrm{Cu}^{2+}$ or $\mathrm{Mn}^{2+}$ ) previously reported as important contributors to enhance laccase activity from other white-rot fungi $[38,39]$. The recovery yield was increased by ammonium sulfate precipitation; however, the highest result was obtained when using ion exchange chromatography. In fact, ion exchange chromatography proved to be a good method for the laccase recovery, but it has a much higher cost when compared to ATPSs.

Different approaches for using fungal laccases are reported in the literature depending on the application or values of enzymatic activity achieved after fermentation. In the most common industrial applications, which include delignification of lignocellulosic materials and effluents decolorization, fungal laccases are used as obtained from the fermentation broth without any special treatment besides filtration to separate the extract from the mycelium [40]. Nevertheless, when laccase is used in bioprocesses like preparation of biosensors, drug synthesis or degradation of phenolic

\section{Table 6}

Laccase recovery by lyophilization, ammonium sulfate precipitation, ultrafiltration or ion exchange chromatography.

\begin{tabular}{ll}
\hline Method & Activity yield (\%) \\
\hline Lyophilization & 48 \\
Ammonium sulfate precipitation & 63 \\
Ultrafiltration & 41 \\
Ion exchange chromatography & 92 \\
\hline
\end{tabular}

compounds present in drinks, higher levels of purity are required and the enzymatic extract have to be carefully purified [41]. Thus, it is important to find suitable methodologies to achieve the purification levels needed in each specific application. In this work it was proved that ATPS provided a partial purification of $P$. cinerea laccase and contributed to an increase of the enzymatic activity. Therefore, this methodology can be suitable for the recovery of laccases with application in industrial bioprocesses where some purity level is required.

Furthermore, it merits emphasizing that UCON is a temperatureresponsive (or thermoseparating) polymer. When heated above the critical temperature (about $50^{\circ} \mathrm{C}$ ), UCON separates from the aqueous solution, thus facilitating polymer recovery and reutilization. Additionally, the use of UCON phosphate salt ATPSs for commercial laccase partition was recently evaluated, being demonstrated to be a promising alternative for laccase recovery [23]. The present study is a sequence of this previous work, and demonstrates that the application of these different ATPSs for laccase recovery from complex fermentation media produces also good results.

The use of ATPS for laccase recovery from culture media has been few explored up till now. Besides the application for pure commercial laccase partition [23,31], only three other studies reporting the use of ATPSs for laccase purification were recently published. All these studies concluded that ATPSs have potential for application in downstream processes in the recovery and primary purification of laccase from fermentation medium. The present study also contributes for the development of this research area, since it was found that ATPSs are good alternatives over the conventional concentration and purification methods, to recover laccase from complex fermented medium.

\section{Conclusions}

UCON-Potassium phosphate salts ATPSs demonstrated to be a promising alternative for laccase recovery from fermentation media. When used for the recovery of $P$. cinerea laccase from complex fermented medium, high laccase activity was obtained in the bottom phase, while some contaminants seemed to be eliminated to the top phase of the biphasic systems. A comparison with conventional concentration and purification methods revealed that ATPSs were a good alternative for laccase recovery, providing high protein yield and enzyme activity, with reduced time and cost.

\section{Acknowledgements}

Sérgio Moreira gratefully acknowledges the financial support from Conselho Nacional de Desenvolvimento Científico e Tecnológico (CNPq, Brazil), and Sara C. Silvério acknowledges her Ph.D. grant (SFRH/BD/43439/2008) from Fundação para a Ciência e a Tecnologia (FCT, Portugal).

\section{References}

[1] C. Mougin, C. Jolivalt, P. Briozzo, C. Madzak, Environ. Chem. Lett. 1 (2003) 145.

[2] P.M. Coll, J.M. Fernandéz-Abalos, J.R. Villanueva, R. Santamaría, P. Pérez, Appl. Environ. Microbiol. 59 (1993) 2607. 
[3] M.C.N. Saparrat, F. Guillén, A.M. Arambarri, A.T. Martínez, M.J. Martínez, Appl. Environ. Microbiol. 68 (2002) 1534.

[4] K.M. Park, S.S. Park, J. Microbiol. Biotechnol. 18 (2008) 670.

[5] V. Madhavi, S.S. Lele, BioResources 4 (2009) 1694.

[6] D. Rochefort, D. Leech, R. Bourbonnais, Green Chem. 6 (2004) 14.

[7] S.L. Moreira, Caracterização de lacase de Peniophora cinereae estudo do potencial de aplicação biotecnológica, in: Ph.D. Thesis, Engineering School of Lorena, University of São Paulo, Portuguese, 2012

[8] S.C. Silvério, S. Moreira, A.M.F. Milagres, E.A. Macedo, J.A. Teixeira, S.I. Mussatto, Bioprocess. Biosyst. Eng. 36 (2013) 365.

[9] D. Shukla, B. Patel, H. Modi, B.R.M. Vyas, J. Environ. Biol. 32 (2011) 713.

[10] V. Elisashvili, E. Kachlishvili, J. Biotechnol. 144 (2009) 37.

[11] P.A. Albertsson, Partition of Cell Particles and Macromolecules, third ed., John Wiley and Sons, New York, 1986.

[12] M. Rito-Palomares, C. Dale, A. Lyddiatt, Biotechnol. Tech. 12 (1998) 711.

[13] R. Hamamoto, M. Kamihira, S. Lijima, J. Ferment. Bioeng. 82 (1996) 73.

[14] F. Luechau, T.C. Ling, A. Lyddiatt, Sep. Purif. Technol. 68 (2009) 114.

[15] O. Aguilar, V. Albiter, L. Serrano-Carreón, M. Rito-Palomares, J. Chromatogr. B 835 (2006) 77

[16] K. Mayolo-Deloisa, M.R. Trejo-Hernández, M. Rito-Palomares, Process Biochem. 44 (2009) 435

[17] K. Ratanapongleka, Songklanakarin J. Sci. Technol. 34 (2012) 69.

[18] A. Prinz, T.Zeiner, T. Vössing, I. Schüttmann, H. Zorn, A. Górak, Chem. Eng. Trans. 27 (2012) 349.

[19] J. Persson, H.-O. Johansson, F. Tjerneld, J. Chromatogr. A 864 (1999) 31.

[20] J. Persson, A. Kaul, F. Tjerneld, J. Chromatogr. B 743 (2000) 115.

[21] S. Saeki, N. Kuwahara, M. Nakata, M. Kaneko, Polymer 17 (1976) 685.

[22] S.C. Silvério, O. Rodríguez, J.A. Teixeira, E.A. Macedo, J. Chem. Eng. Data 55 (2010) 1285.
[23] S.C. Silvério, O. Rodríguez, A.P.M. Tavares, J.A. Teixeira, E.A. Macedo, J. Mol. Catal B: Enzym. 87 (2013) 37.

[24] R. Bourbonnais, M.G. Paice, B. Freiermuth, E. Bodie, S. Bornemann, Appl. Environ. Microbiol. 63 (1997) 4627.

[25] M.M. Bradford, Anal. Biochem. 72 (1976) 248

[26] S.C. Silvério, S. Moreira, A.M.F. Milagres, E.A. Macedo, J.A. Teixeira, S.I. Mussatto, Anal. Biochem. 421 (2012) 719.

[27] P. Baldrian, FEMS Microbiol. Rev. 30 (2006) 215.

[28] R. Schmid, Adv. Biochem. Eng. 12 (1979) 41.

[29] P.V. Iyer, Process Biochem. 43 (2008) 1019.

[30] K. Modaressi, K.E. Taylor, J.K. Bewtra, N. Biswas, Water Res. 39 (2005) 4309.

[31] E. Lladosa, S.C. Silvério, O. Rodríguez, J.A. Teixeira, E.A. Macedo, J. Chem. Thermodyn. 55 (2012) 166-171.

[32] B.R. Babu, N.K. Rastogi, K.S.M.S. Raghavarao, Chem. Eng. Process. 47 (2008) 83.

[33] K.E. Nandini, N.K. Rastogi, Appl. Biochem. Biotechnol. 163 (2011) 173.

[34] B.S. Priyanka, N.K. Rastogi, K.S.M.S. Raghavarao, M.S. Thakur, Process Biochem. 47 (2012) 1358

[35] M. Akhtar, R.A. Blanchette, G. Myers, K. Kirk, An overview of biomechanical pulping research, in: R.A. Young, M. Akhtar (Eds.), Environmentally Friendly Technologies for Pulp and Paper Industry, John Wiley and Sons, New York 1998.

[36] K. Mayolo-Deloisa, C. Machín-Ramírez, M. Rito-Palomares, M.R. TrejoHernández, Chem. Eng. Technol. 34 (2011) 1368.

[37] W. Wang, Int. J. Pharm. 203 (2000) 1.

[38] P. Baldrian, J. Gabriel, FEMS Microbiol. Lett. 206 (2002) 69.

[39] A.M. Farnet, G. Gil, E. Ferre, Chemosphere 70 (2008) 895.

[40] N.K. Pazarlioğlu, M. Sariișik, A. Telefoncu, Process Biochem. 40 (2005) 1673

[41] R. Rawal, S. Chawla, C.S. Pundir, Anal. Biochem. 419 (2011) 196. 